\title{
Do Specific Combinations of Parent-Child Relationships Predict Moral Values?
}

\section{Julie Grégoire \& Lieven J.R. Pauwels}

To cite this article: Julie Grégoire \& Lieven J.R. Pauwels (2019): Do Specific Combinations of Parent-Child Relationships Predict Moral Values?, Deviant Behavior, DOI: 10.1080/01639625.2019.1627018

To link to this article: https://doi.org/10.1080/01639625.2019.1627018

$$
\text { 册 Published online: } 15 \text { Jun } 2019 .
$$

Submit your article to this journal $\pi$

Џll Article views: 10

View Crossmark data $\nearrow$ 


\title{
Do Specific Combinations of Parent-Child Relationships Predict Moral Values?
}

\author{
Julie Grégoire ${ }^{a}$ and Lieven J.R. Pauwels ${ }^{b}$ \\ apolitical Science, and Criminology (Belgium) and member of the Center-Research-Intervention-Youth, Liège, \\ Belgium; 'bProfessor of Criminology at Ghent University, Ghent, Belgium
}

\begin{abstract}
In this study we examined to what extent different combinations of parentchild relationships explain adolescents' moral values and whether the influence of school and peers predicts moral values. We also investigated whether anticipated shame and anticipated guilt predict moral values. A convenience sample of 1,120 adolescents, including 120 adolescents in youth custody, was used. Results suggest that combinations of parentchild relationships do not predict moral values, that school and peers are significant predictors of adolescents' moral values, and anticipated shame and guilt do not consistently and equally predict moral values. Results were highly similar for boys and girls.
\end{abstract}

\section{ARTICLE HISTORY}

Received 22 October 2018

Accepted 10 April 2019

Numerous criminologists support the assumption that having low conventional beliefs (e.g. Hirschi 1969), definitions favorable to the violation of law (Akers 1998), or low moral values (e.g. Ivert et al. 2018; Svensson, Pauwels, and Weerman 2010), plays a central role in the explanation of crime. Yet, as some scholars suggest, the concept of morality has been largely ignored in criminological inquiries (Wikström 2010, 2017). This discrepancy seems odd when one looks at how the key construct of moral values (or moral beliefs) and morality are measured. Scholars commonly consider how right or wrong it is to conduct some kinds of behavior. An increasing number of studies also report that not only moral values but also moral emotions, such as anticipated feelings of shame and guilt, are negatively associated with offending (e.g. Rebellon et al. 2010; Svensson, Pauwels, and Weerman 2017a). Wikström et al. (2012) have argued that personal evaluation of norms, backed up by moral emotions like shame and guilt together represent morality much better than each separate dimension. Many scholars have argued that the way people come to acquire specific moral rules and related moral emotions is part of a moral education process during which socialization agents such as family, peers, and school play an important role (e.g. Grusec 2011; Wikström et al. 2012). An increasing number of studies have investigated the relationships between these socialization agents as determinants of moral values and moral emotions (Pauwels and Svensson 2010; Svensson, Robert, Pauwels, Weerman, Gerben, and Bruinsma 2017b).

Several studies have examined relationships between moral emotions and moral values or measures of the bonds with socialization agents (e.g. Malti et al. 2013; Tangney and Dearing 2002). However, with the exception of a study by Svensson, Robert, Pauwels, Weerman, Gerben, and Bruinsma (2017b), we are unaware of any study that has tested the statistical effects of three major socialization agents family, school, and peers - simultaneously and distinguished between the dimensions of morality, that is, moral values, anticipated shame, and anticipated guilt. Further, social bonds with socialization agents, especially with parents, have been largely investigated in terms of "good or bad" attachment. The complexity of social bonds and underlying mechanisms that may explain relationships between 
these bonds and delinquency are rarely investigated (e.g. Svensson 2004), yet knowledge could be gained by studying how these bonds are established through a combination of relationships (Weerman 1998). Further, existing studies that have examined anticipated shame have failed to differentiate between the significant others toward whom one feels ashamed (parents, teachers, and peers).

Furthermore, although a well-established gender gap exists in terms of crime involvement (e.g. De Coster, Heimer, and Cumley 2013; Jennings et al. 2010), a number of studies have shown that common factors can explain crime involvement for both males and females (Ivert et al. 2018). However, few studies that have addressed socialization agents and morality have investigated to what extent relationships and mechanisms between these factors are similar for boys and for girls (e.g. Svensson, Robert, Pauwels, Weerman, Gerben, and Bruinsma 2017b). And finally, nearly all studies interested in these factors have concentrated on communitybased samples (i.e. adolescent students), yet we know that adolescents who tend toward serious offending do not attend school regularly (e.g. Remacle, Jaspart, and De Fraene 2012). This specificity could lead to misinformation about this more problematic population and to over- or underestimate some factors or mechanisms.

This study's main research question is: 'are different combinations of parent-child relationships associated with differences in moral values, and what is the effect of other socialization agents (school and peers) and also of anticipated moral emotions on moral values?' This study used latent class analysis (LCA) to investigate specific combinations of parent-child relationships in a sample of adolescents from schools and adolescents from juvenile detention centers. LCA, rarely used in criminology, enables one to study the effect of specific combinations of variables on a specific outcome. This study used multinomial logistic regressions (MLR) to investigate whether belonging to one of these combinations, and also whether socialization agents such as school and peers, statistically predict adherence to conventional moral values (with moral values as a dependent variable), separately for boys and for girls. Finally, this study investigated to what extent moral emotions of anticipated guilt and anticipated shame (distinguishably toward parents, teachers, and peers) statistically predict moral values. This study was guided by developmental ecological models that posited that socialization agents that are dependent on the sociological characteristics of communities influence the development of moral norms and moral emotions (e.g. Bronfenbrenner 1979; Gorman-Smith, Tolan, and Henry 1999; Wikström 2017).

\section{Theoretical framework}

Moral values is a central concept in criminological theory and research (e.g. Agnew and White 1992; Reckless 1967; Sutherland 1947). In the framework of situational action theory (SAT), morality (or overall moral propensity, in the language of SAT) is regarded as the main individual-level cause of crime; moral propensity explains why some people do not perceive the commitment of crime as an action alternative (e.g. Wikström 2010). The most important elements of moral propensity are moral values and the moral emotions of shame and guilt. SAT considers crimes as acts of moral rule breaking. Crime is an outcome of a perception-choice process, that is, a "process of perceiving action alternatives and making choice in relation to a motivation" (Wikström et al. 2012: 11). This process is guided by the interaction between a person's crime propensity and a criminogenic exposure. The major component of a person's crime propensity is his or her morality (moral values and moral emotions). A person's moral values and moral emotions, in combination with the moral characteristics of the setting in which an action takes place, act as a moral filter in the perception of opportunities to offend: a person with a lawabiding (or conventional) morality will not tend to see crime as an alternative action (Wikström 2010). Several empirical (partial) tests of SAT show that moral values and offending are negatively associated (e.g. Ivert et al. 2018; Svensson, Pauwels, and Weerman 2010, 2017a; Svensson et al. 2013).

A person's moral values and moral emotions result from a socialization process (Elias et al. 2008; Wikström and Sampson 2003). ${ }^{1}$ A successful socialization process will lead to the internalization of

\footnotetext{
${ }^{1}$ When we use the concept of socialization, we do not suggest that moral norms are mainly the product of learning processes, i.e. we reject the 'Blank Slate view' (Pinker 2004) and recognize the importance of biosocial interactions as 'causes of the causes' of crime. In line with evolutionary biology, humans' capacity for morality can be seen as a consequence of the need to cooperate (Krebs 2011; Tomasello 2016).
} 
moral norms and the development of a moral sense (Svensson et al. 2013). On the contrary, a poor socialization process will negatively affect internalization and development of moral norms and moral emotions. According to Wikström et al. (2012), social institutions, such as family, school, and peers are major driving forces in the development of morality. ${ }^{2}$ The bioecological model of Bronfenbrenner and colleagues (Bronfenbrenner and Ceci 1994; Bronfenbrenner and Morris 2006) also maintain that children evolve in different social environments that influence each other, and together, form a moral context. To capture the complexity of social bonds, one must study combinations of dimensions (Weerman 1998).

Family is considered to be the primary socialization agent and the most influential in the development of moral values and emotions (e.g. Grusec 2011; Lewis 1992; Tangney and Dearing 2002; Weerman 1998). School and peers are secondary socialization agents (e.g. Gecas 2000; Svensson, Pauwels, and Weerman 2017a; Svensson et al. 2013). While the primary socialization agent lays the foundation for the socialization process, secondary socialization agents consolidate or adjust these moral values and emotions. Effective parenting leads to the internalization of conventional norms and a moral sense of what is right or wrong, including feelings of guilt and shame when committing a crime (Hardy, Padilla-Walker, and Carlo 2008; Tangney and Dearing 2002).

It is assumed that the school social bond will consolidate this process. At school, youths learn skills and attitudes, and also norms and values that they further internalize (Svensson, Pauwels, and Weerman 2017a). School is assumed to adjust or consolidate not only moral values but also moral emotions (shame and guilt) previously and concurrently learned from parents (e.g. Gecas 2000). But to integrate the routine law-conforming expectations of schools, more specifically of teachers, youths need to be connected with them, or in other words, attached (Hirschi 1969). Although family and school are considered to be "vertical" socialization agents because external authority is linked to obedience, respect for social order, and convention, friends are a "horizontal" socialization agent usually marked by reciprocity and group solidarity instead of authority (Horn, Daddis, and Killen 2008). ${ }^{3}$

During adolescence, youths build new emotional relationships, and peer groups exert increasing influence as their role in the adolescents' life becomes more important (Hart and Carlo 2005; Weerman 2004). As such, norms and values of other youths will have a significant influence on the moral values and emotions of the adolescent. Youths normally prefer to associate with others who share similar norms and values (e.g. Hirschi 1969; Sampson and Laub 1993), and this preference (captured by control theory's adagium 'birds of a feather flock together') consolidates adolescents' moral values and emotions (Akers 1998; Rebellon et al. 2010). This process could also lead an adolescent to adjust his or her moral values.

Moral values (or moral rules) can be defined as "what a person perceives as right or wrong to do" (Wikström et al. 2012: 14), and moral emotions can be considered as the consequence of moral values, or indicators of the strength of particular moral values (Wikström et al. 2012). Moral emotions play a major role in guiding a person's choice of behavior (Lewis 1992; Sheikh and JanoffBulman 2010; Tangney and Dearing 2002). According to several authors, shame and guilt are the most important moral emotions (e.g. Elster 1999; Tangney, Stuewig, and Mashek 2007).

Shame arises when an individual commits an act that breaches internalized norms and then feels that he or she has failed to abide by the norms of the group (Elster 1999; Svensson 2004; Svensson et al. 2013). The important issue here is not the act in itself, but the fact that the individual has committed that act: the focus is on the individual's perception of one's self through the eyes of others and their disapproval. Elster pointed out that "the anticipation of shame acts as a powerful regulator of behavior" (1999, p.154). This is so because the anticipation of moral emotions makes individuals aware of the potential costs of breaking moral rules.

\footnotetext{
${ }^{2}$ They also noted that these institutions have a different impact depending on the "person's biological maturation and social and cognitive development" (Wikström et al. 2012: 32). Nevertheless, biological factors are not discussed in this paper.

${ }^{3}$ Of course we recognize exceptions to this observation, e.g. in troublesome youth groups or gangs.
} 
Guilt emerges when an individual commits an act that breaches norms and values and then judges this act of violation as morally wrong (Elster 1999). The individual feels he or she has failed to live up to their own internalized moral rules. This feeling implies that an individual is able to differentiate between what is morally right or wrong (Gecas 2001). Shame is often considered to be the most painful and intensive emotion because it is related to the individual's perception of the self, while guilt is related to a specific act (Elster 1999).

Shame and guilt may have an effect without an actual act of rule breaking. Individuals may anticipate moral emotions that can be associated with behavior (De Boeck, Pleysier, and Put 2017; Tangney, Stuewig, and Mashek 2007). On the basis of their previous experiences, individuals learn their positive and negative emotional reactions and can then anticipate their feelings (Baumeister, Stillwell, and Heatherton 1994). Several studies have shown that anticipated feelings of shame and guilt play an important role in restraining oneself from committing crimes (e.g. Rebellon et al. 2010; Tangney and Dearing 2002; Tibbetts 2003), and most individuals strive to avoid these feelings because they can be emotionally painful (e.g. Elster 1999; Tangney, Stuewig, and Mashek 2007).

Finally, while several scholars argue that male criminality and female criminality have to be studied independently because the underlying causes differ (Blokland and Rianne 2010; Fontaine et al. 2009), a significant number of studies show that common factors may explain the different crime involvement of boys and girls and why boys engage more often in crime than girls do (De Coster, Heimer, and Cumley 2013; Ivert et al. 2018; Meier 2010; Moffitt et al. 2001). ${ }^{4}$

\section{Previous studies on socialization agents and moral emotions}

To establish the importance of family as the first and most important socialization agent, numerous studies have investigated the emotional relationship between parents and children through attachment or bond with parents measures (e.g. Grusec 2011; Scheff 1997; Svensson et al. 2013). A secure parent-child attachment influences a child's well-being and is the base for a child's healthy and harmonious development (Bowlby 1982). It is well established that stronger bonds with parents are associated not only with a stronger conviction to act in accordance with parents' conventional rules of conduct (Hirschi 1969), but also with a lower propensity to commit crimes (e.g. Svensson et al. 2013). Although for many years studies have shown that parental affection acts as a promotive factor against criminal behaviors in their children (e.g. Loeber and Stouthamer-Loeber 1986; McCord 1986), the mechanisms that explain relationships between attachment and delinquency have been poorly investigated.

Criminological research has also investigated parental supervision in the family socialization process (e.g. Hardy, Padilla-Walker, and Carlo 2008; Svensson, Pauwels, and Weerman 2017a; Svensson et al. 2013), and has suggested that supervision is more effective when there is a positive parent-child relationship (e.g. Grusec 2011; Steinberg 2001). Other factors key to the parental socialization process are child disclosure and parental solicitation/concern (Stattin and Kerr 2000). Stattin and Kerr (2000) revealed that child disclosure, that is, openly communicating without being prompted, is a more important predictor of delinquent behavior than is parental control or supervision. Child disclosure implies trust and positive parent-child relationships that leads to communication. Stattin and Kerr (2000) also differentiate parental control and parental solicitation. Parental control (or supervision) is about imposing rules and restrictions, while parental solicitation is about asking questions. Although numerous criminological studies are interested in parent-child bonds (or relationships), the complexity of this social bond and underlying mechanisms explaining relationships between social bonds and delinquent behavior are rarely investigated (e.g. Svensson 2004).

To capture this complexity, on the basis of several researchers, Skinner, Johnson, and Snyder (2005) listed a set of themes traced in various forms and identified central themes or dimensions. Indeed, beyond attachment, in later childhood, the development of delinquent behavior has been

\footnotetext{
${ }^{4}$ The discussion between scholars on this topic is confused by different conceptions of causes or mechanisms (Wikström 2007).
} 
linked to other aspects of parenting (Hoeve et al. 2009). Skinner, Johnson, and Snyder (2005) distinguish between six dimensions of parenting: warmth, rejection, structure, chaos, autonomy support, and coercion. No other criminological research that we are aware of has used these alternative dimensions simultaneously to investigate parental socialization. Warmth is the expression of love, appreciation, kindness, and regard. As for Rejection, this dimension is the opposite of warmth. Rejection is the expression of hostility, harshness, aversion, and explosiveness from parents. Several studies underlined the role of such parental practices in explaining delinquent behaviors (e.g. Pardini, Fite, and Burke 2008; Steinberg and Silk 2002), and some indicate that harsh parenting is one of the most important predictors of delinquency (Tanner-Smith, Wilson, and Lipsey 2013). Structure is not about control and rules, but is about "provision of information about pathways to reach desired outcomes" (Skinner, Johnson, and Snyder 2005: 188), predictability, and consistence, but also clear expectations. The opposite of structure is chaos. This goes beyond the lack of structure and refers to noncontingency of parental behaviors, unpredictability, and arbitrariness. Scholars such as Parker and Benson (2004) showed that high levels of parental involvement in structuring children's activities have been associated with lower rates of delinquency. When parents practice autonomy support, they are encouraging freedom of action and expression, as well as independent problem solving and choice. Contrary to this practice, coercion is about parental demand for strict obedience, extending to overcontrolling and intrusive autocratic parenting. These two last dimensions have been largely discussed by scholars such as Colvin, Cullen, and Ven (2002) in their theory of differential coercion and social support (see also Colvin 2000; Cullen 1994). But, they conceptualized coercion and social support more broadly than Skinner, Johnson, and Snyder (2005) did with coercion and autonomy support. Thereby, the six-factor model of Skinner, Johnson, and Snyder (2005) could be subsumed in the theoretical model of Colvin, Cullen, and Ven (2002).

Research increasingly recognizes the importance of using multiple dimensions, both positive and negative, to identify parenting combinations and capture the complexity of parent-child relationships (e.g. Kim et al. 2013; Nelson et al. 2011). Skinner, Johnson, and Snyder (2005) propose to use the six dimensions in combination to create typologies of parenting.

Several criminological studies have shown anticipated shame and anticipated guilt to be negatively related to offending (e.g. Rebellon et al. 2010; Wikström and Svensson 2008), meaning people do not feel anticipatively ashamed or guilty for rule-breaking acts. Shame and guilt emerge during socialization processes (e.g. Grusec 2011; Tangney and Dearing 2002) and are internalized. Once internalized, the "anticipated" (fear of) shame causes an individual to restrain him- or herself from committing a crime because they seek to live up to the standards and expectations of significant others with whom they share norms and values. In other words, they fear social disapproval. "Anticipated" (fear of) guilt prevents an individual from committing a criminal act because they consider the act to be morally wrong (Svensson et al. 2013). "Anticipated" moral emotions, which are personal expectations of shame and guilt in certain situations, may be indicators of an individual's moral values. Although several psychological studies have examined shame and guilt, the study of both is rare in criminology (Svensson et al. 2013).

In the field of criminology research, while moral beliefs have been frequently studied (e.g. Mazerolle and Piquero 1997; Tibbetts and Myers 1999) and underlined in some criminological theories such as social control (Hirschi 1969) and social learning (Akers 1985), the key mechanisms linking morals to delinquent behaviors and the operationalization of morals are rarely clearly explained. According to Wikström and Treiber (2007), "[the] strength of a moral belief can be characterized as 'the intensity of the moral emotions: the potency of the feelings of guilt and shame if violating a moral rule"' (p.246). Four major theories explicitly mention the role of moral emotions: the SAT of Wikström et al. (2012), Wikström (2017) the Reintegrative Shaming Theory of Braithwaite (1989) (Svensson, Pauwels, and Weerman 2017a), the Social Learning Theory of Akers $(0,1998)$, and wide versions of Rational Choice Theory and behavioral economics (Opp and Pauwels 2018), where moral emotions are treated as (psychological) costs. However, they treat moral emotions differently. Although early criminological research focused on shame and considered it 
to be the most important predictor of offending, recent research shows that guilt has a higher predictive power in explaining offending in children and young adolescents (e.g. Pauwels and Svensson 2015). Further, measures of shame vary among studies, and some studies that measured shame were, in fact, measuring guilt (Svensson et al. 2013). This inconsistency may be the result of differing operationalization of shame across studies. When examining anticipated shame, studies generally do not distinguish between significant others: a single dimension is often assumed for parents, teachers, and peers (e.g. Svensson, Pauwels, and Weerman 2017a; Wikström and Svensson 2008), which may lead to inconsistent results. When investigating the influence of different socialization agents on individuals' moral rules and moral emotions, as well as the underlying mechanisms, one must distinguish between significant others in terms of dimensions of anticipated shame in order to achieve accurate results.

In addition to these theoretical considerations are gender considerations. Studying mechanisms between gender-based socialization and morality is quite uncommon. To our knowledge, Svensson, Pauwels, and Weerman (2017a), using data from a Dutch two-wave panel study, are the only researchers to have investigated links between moral values and moral emotions regarding social bonds with parents, school, and peers, while simultaneously investigating differences between boys and girls, in terms of these same factors. Although they found that gender differences exist in the level of morality, they found no large differences between boys and girls in the effect of socialization variables on morality dimensions, and they suggest that similar factors explain crime propensity for boys and for girls.

It appears that no criminological study has investigated the factors mentioned above using a delinquent subsample. All previous studies used community-based samples, principally for questions of representation and reliability. However, although these studies are useful for reaching an understanding of mechanisms or typologies of variables, it is well know that these samples collected in schools underrepresent delinquents, notably because they do not regularly attend school (e.g. Remacle, Jaspart, and De Fraene 2012), and that behavior patterns in community-based samples do not generalize well to offenders' samples (Piquero and Brame 2008).

In case of a convenience sample to study mechanisms or typologies, providing maximal heterogeneity is extremely important. Therefore, combining a delinquent subsample (e.g. a custodial population) and a community-based sample would provide a heterogeneous sample regarding delinquency, but also social bonds, and will enable to investigate parent-child relationships typologies more globally.

\section{The present study}

This study seeks to identify various combinations of adolescent boys and girls in a parent-child relationship's dyad that might predict low or high moral values and to determine to what extent covariates such as anticipated shame, anticipated guilt, and socialization indicators for school and peers predict low or high moral values. More specifically, this study aims to identify combinations of parent-child relationships and then to investigate whether

H1. Combinations of parent-child relationships predict individual differences in moral values: combinations associated with a promotive parent-child relationship are related to high adherence to conventional moral values, and inversely for combinations associated with a detrimental parent-child relationship.

H2. Anticipated moral emotions predict moral values: higher levels of anticipated guilt and anticipated shame toward parents, teachers, and peers predict higher adherence to conventional moral values.

H3. Socialization agents, such as school and peers, predict individual differences in moral values: the stronger the school social bond, the higher the likelihood of adherence to conventional 
moral values, and the greater extent to which adolescents are exposed to peer delinquency, the less likely they are to adhere to conventional moral values.

H4. Although effect sizes may be different for boys and for girls, we expect the results to be quite similar for both boys and girls (same mechanism).

\section{Methodology}

\section{Data}

\section{Participants}

Data were collected between November 2015 and October 2016. In total, 1120 adolescents in Belgium (52.8\% girls, $47.2 \%$ boys) participated in the study. The sample comprised two subsamples: one, adolescents from secondary schools $(n=1000 ; 56.1 \%$ girls, $43.9 \%$ boys $)$ ages $14-18(M=15.93$; $S D=1.12)$, and two, adolescents in custody $(n=120 ; 75.0 \%$ boys, $25.0 \%$ girls $)$ ages $13-19(M=$ 15.79; $S D=1.41$ ). An information sheet was distributed to adolescents that informed parents about the study and stated that their children's participation could be refused (passive informed consent).

For the subsample of adolescents from schools, 38 schools were contacted in the cities of Liège, Verviers, and Charleroi (three large cities in the French-speaking region of Belgium); 18 schools responded and 6 schools agreed to cooperate in the study. This subsample included a relatively high proportion of adolescents with at least one or both parents a non-Belgian native $(38.3 \%)$. The majority of adolescents were involved in the highest form of education (68.2\%), 28.6\% were enrolled in "technical education," and 3.2\% were enrolled in "vocational education." Official register data (ETNIC 2013-2014) are 51.9\%, 24.9\%, and 23.2\%, respectively, for these forms of secondary education in the cities of Liège, Verviers, and Charleroi. Because of the nonrandom selection of schools in these cities, this subsample was not perfectly representative of Belgians from the French region of the country but varied highly in terms of ethnicity and educational background.

For this school subsample, two methods, using the same questionnaire, were used for data collection. The first method ( $48.2 \%$ of the school subsample) consisted of home completion of the questionnaire via the Internet. This method was chosen to ensure voluntary participation and nonbiased results. At each school, the researcher completed a 10-min presentation of the research protocol in classes. A handout containing essential information about the research and a Web link for home completion of the questionnaire was then distributed to adolescents. This first method led to an overrepresentation of girls (66.7\%) and of adolescents in the highest form of education (89.4\%). ${ }^{5}$ To rebalance this subsample, we used a second method that targeted adolescents enrolled in technical and vocational education. This method consisted of a questionnaire administered to classes (9-23 students), supervised by one researcher during a school period of about $50 \mathrm{~min}$. This procedure ensured monitoring and support of adolescents and an opportunity to directly answer any question about the questionnaire. Questionnaires were provided with a paper-and-pencil method or via Web support when computers were available. According to several authors, the use of either of these methods of administration has little or no impact on answers (Lucia, Herrmann, and Killias 2007; Rosenbaum et al. 2006). The questionnaire items had relatively low nonresponse and missing values (maximum 3.8\%). Controlling for age, gender, and education form, there appeared to be no significant effect of the method (at home or in class) on self-reported delinquent acts ( $p=.186)$ (oneway ANCOVA).

For the (delinquent) subsample of adolescents in juvenile custody, the six juvenile detention centers (one designed for girls and five for boys) situated in the French region of Belgium were approached to cooperate in the study, and all accepted. This subsample includes a high proportion

${ }^{5}$ The percentage of respondents is difficult to compute with this method. We estimate this percentage between $10 \%$ and $15 \%$. 
of ethnic minority adolescents (73.8\%). The majority of adolescents came from the lowest form of education (56.7\%), 11.7\% came from "technical education," and $15.8 \%$ came from "general education"; 9.2\% reported being in a "specialized" form of education, meaning they did not have their diploma in primary education, and 6.7\% were out of school (not enrolled). These adolescents came from various areas of Belgium (French region). For Brussels (the capital city of Belgium) and the five provinces (Brabant-Wallon, Liège, Namur, Luxembourg, Hainaut) of the French-speaking region of the country, the percentages were 48.7, 2.5, 18.5, 3.4, 11.8, and 15.1, respectively, with one missing value. This subsample, which showed a level of delinquency higher than that of the other subsample (higher prevalence and greater frequency of several delinquent acts), was integrated to further investigate adolescents' combinations. This subsample was not representative of Belgians from the French region of the country, but it varied in terms of ethnicity, education forms, and locations.

For this subsample, the same researcher went to juvenile custody facilities to collect data. She first went to every open and closed unit to present the research protocol to adolescents. Unit by unit, during a 10- to 15-min period, she explained the objectives of the research, its confidentiality, and the voluntary nature of participation. Adolescents were then given a few days to decide to agree to participate or not to participate. A few days later, adolescents were individually introduced to the research protocol (on paper or via Internet) in a separate room with the researcher as the only other person present. The time of completion varied from 50 to $90 \mathrm{~min}$. Participants could choose to either read the questionnaire themselves or have it read aloud by the researcher. The second solution, considered to invoke better understanding (Marsee and Frick 2007), was chosen in $92.5 \%$ of cases (111 out of 120 adolescents). In total, the research was presented to 213 young people (62 girls and 151 boys), and 30 girls (48.39\%) and 90 boys (59.60\%) agreed to participate (see Authors' anonymity, in press, for the pretest, details on units and on method and administration of questionnaire). Because of the one-by-one procedure and high degree of monitoring and support by the researcher, the questionnaire items had relatively low nonresponse and missing values (maximum 1.7\%).

Our research was approved by the University of Liège ethics review board and by government officials responsible for the juvenile detention facilities. An official letter from the university requested permission to work with the juvenile detention centers.

\section{Operationalization of key concepts}

All constructs are summative scales of several items. These scales can be considered to be Likerttype. Reliability analyses, indicating if measures consistently reflect the construct of interest, were conducted to construct scales. Measures in the "parent-child relationships" section were used for LCA on the entire sample $(N=1120)$, so one single alpha is provided for each scale. Other measures were used for MLR for boys $(n=529)$ and then for girls $(n=591)$, so two alphas are provided (one for boys, the other for girls). Moral values are the dependent variable in the MLR model, while others are the independent ones (or predictors). See the Tables I, II, III and IV for detailed information about the wording, coding, and descriptive statistics of the scales. All the measures were translated into French for the purpose of the research.

\section{Parent-child relationships}

Parental attachment measures adolescents' level of attachment to their parents. The scale consists of four items $(\alpha=.79)$. High scores indicate that adolescent boys and girls have a low level of parental attachment, or in other words, weak emotional bonds with their parents.

Child disclosure indicates to what extent adolescents spontaneously disclose information to their parents. This scale consists of five items $(\alpha=.80)$. High scores indicate adolescents disclose substantial information to their parents.

Parental solicitation indicates whether parents actively solicit information from their children about their activities and whereabouts. This scale is measured by using five items $(\alpha=.72)$. High scores indicate high level of parental solicitation. 
Parental supervision measures to what extent parents control their children's activities. The scale consists of six items $(\alpha=.85)$. High scores indicate respondents are strongly controlled by their parents.

Warmth measures whether adolescents report affection, love, kindness, and regard from their parents. This scale consists of four items $(\alpha=.88)$. High scores indicate adolescents report strong affection, love, kindness, and regard from their parents.

Rejection is conceptualized as the opposite of warmth. It indicates the extent to which parents actively reject and dislike their children. This scale consists of four items $(\alpha=.79)$. High scores indicate adolescents report they are strongly rejected by their parents.

Structure measures the extent to which parents provide support and guidance while their children strive to achieve desired outcomes. This scale consists of four items $(\alpha=.78)$. High scores indicate respondents are strongly supported by their parents when they encounter problems in achieving outcomes.

Chaos indicates whether parents exhibit inconsistent, arbitrary, or unpredictable behaviors or behaviors that make achieving a goal difficult. This scale consists of four items $(\alpha=.79)$. High scores indicate respondents are faced with strong inconsistent, arbitrary, or unpredictable parental behaviors.

Autonomy support measures the extent to which parents encourage their children to express their views and opinions and give weight to these expressions. This scale consists of four items $(\alpha=.82)$. High scores indicate strong autonomy support from parents.

Coercion indicates coercive, overcontrolling, intrusive, and restrictive parenting. This scale consists of four items $(\alpha=.71)$. High scores indicate respondents report strong coercion from their parents.

Parental attachment measures come from Pauwels and Svensson (2010). Child disclosure, parental solicitation, and parental supervision measures come from Stattin and Kerr (2000). The six dimensions of warmth, rejection, structure, chaos, autonomy support, and coercion come from Skinner, Johnson, and Snyder (2005).

\section{Moral values and moral emotions}

Moral values measure respondents' personal evaluation of how right or wrong is the breaching of some rules. The scale consists of 16 items ( $\alpha=.90$ for boys; $\alpha=.88$ for girls). High scores indicate that respondents strongly adhere to conventional moral values. Because this scale did not follow a normal distribution, we used 25th and 75th percentiles of the distributions as cut-off points in order to divide the distribution into three categories. For the first category, low morality, the defining ranges were 0 to 2.250 for boys $(n=125)$ and 0 to 2.500 for girls $(n=146)$. For the second category, moderate morality, the defining ranges were 2.251 to 2.999 for boys $(n=$ $229)$ and 2.501 to 3.187 for girls $(n=285)$. Finally, for the third category, high morality, the defining ranges were 3.000 to 4.000 for boys $(n=143)$ and 3.187 to 4.000 for girls $(n=129)$. There were $6.05 \%$ missing values for boys $(n=32)$ and $5.25 \%$ for girls $(n=31)$.

Anticipated guilt feelings measure the anticipated level of guilt reported by adolescents if they were to be caught for an offense. This scale consists of six items ( $\alpha=.80$ for boys; $\alpha=.77$ for girls). High scores indicate adolescents would feel extremely guilty.

Anticipated shame feelings measure the anticipated level of shame reported by respondents if they were to be caught for an offense. This scale consists of six items. Two questions were asked three times to measure shame felt toward different significant others (parents, teachers, and peers). Items 1 and 4 measured anticipated shame toward one or both parents $\left(\mathrm{r}^{6}=.81\right.$ for boys; $\mathrm{r}=.84$ for girls). Items 2 and 5 measured anticipated shame toward one or several teachers $(r=.82$ for boys; $r=.87$ for girls). Items 3 and 6 measured anticipated shame toward peers $(r=.79$ for boys; $r=.81$ for girls).

${ }^{6} \mathrm{Here}$, we indicate correlations instead of alphas. Alphas should be based on at least three items. Correlations between .70 and .90 indicate high and positive relationships between variables (Hinkle, Wiersma, and Jurs 2003). 
High levels mean respondents would feel extremely ashamed if they had been caught for an offense they had committed.

Measures of moral values and moral emotions were based on the questionnaire of the PADS+ study of Wikström et al. (2012), also used by Svensson et al. (2013), who investigated moral values and moral emotions and their determinants.

\section{Secondary socialization indicators}

School social bond measures the extent of attachment and commitment of respondents to school and to classmates and teachers. The scale consists of seven items ( $\alpha=.66$ for boys; $\alpha=.69$ for girls). These relatively low alphas suggest that results be interpreted with caution. High scores mean respondents have a high level of bond to their school. These measures were based on those of Svensson et al. (2013).

Peer delinquency measures exposure to peer delinquency ( $\alpha=.93$ for boys; $\alpha=.89$ for girls). High scores mean that all the adolescents' peers have committed several types of delinquent or deviant acts. These measures were based on the questionnaire of Huizinga, Esbensen, and Weiher (1991).

\section{Background variables (statistical control variables)}

Gender refers to the biological sex of the respondents. Gender is coded 0 for girls and 1 for boys.

Age consists of four categories: adolescents who are age 13 years or younger (coded 1), adolescents ages 14-15 years (coded 2), adolescents ages 16-17 years (coded 3), and adolescents age 18 years or older (coded 4$)^{7}$

\section{Analytical strategy}

We used LCA to identify combinations of the parent-child relationships. LCA is a "personcentered" versus "variable-centered" approach in that LCA goes several statistical approaches further by focusing not on variables in isolation, but on groups of individuals with particular combinations of variables (Muthén and Muthén 2000). Frequently used in psychological studies on parenting (e.g. Kim et al. 2013; Luyckx et al. 2011), LCA is rarely used in criminological research. Yet, this approach is useful for deriving classes or combinations of variables that could help identify nuance and clarify previous results about parent-child relationships and its link with moral values and emotions. Furthermore, when one is interested in finding heterogeneous groups, LCA is useful when data include heterogeneous individuals (Muthén and Muthén 2000).

First, we calculated descriptive statistics using adolescents' responses on the parent-child relationships scales. Then, we used $z$-scores to set the sample mean to zero and standardize all scales in order to identify the ones that most strongly characterized each class. Variables with a $\mathrm{z}$-score greater than 0.30 or less than -0.30 were used to define the classes (e.g. Lanctôt, Lemieux, and Mathys 2016). We considered various indicators to determine the number of classes to retain: iterations, which ensure as little variation as possible, and the Bayesian information criterion, which has to be as small as possible (Nylund, Asparouhov, and Muthén 2007). Further, each class also had to include at least $5 \%$ of the sample in order to ensure acceptability for further analyses. Taking all these criteria into account, we retained a three-class solution as the best representation of our data (see Appendix, Table III for details). Each of the three classes represents a different combination of variables that represents a specific parent-child relationship. We describe these combinations in the Results section of this article.

To determine whether these combinations would predict higher or lower moral values, we performed MLR analyses separately for boys $(n=529)$ and for girls $(n=591)$, with moral values

${ }^{7}$ Age is considered to be a control variable. Socioeconomic status (SES) was not taken into account as a control variable because the adolescents were often unaware of their parents' educational level or type of job (often used to measure SES). 
as a dependent variable and combinations of parent-child relationships as independent variables. ${ }^{8}$ In preliminary analyses, we tested for the influence of background variables, such as ethnicity and age. We found ethnicity was not significantly correlated with moral values, but age was marginally associated with lower moral values for boys and for girls. Therefore, we added age as a control variable. Then, we tested to what extent anticipated emotions, and also school social bond and exposure to peer delinquency, predicted moral values. We describe the findings in the Results section.

Multicollinearity was not a problem in our analyses (see the correlation matrix in the Appendix, Table II), in which the highest variance inflation factor was 2.45 , well below 10 , the commonly accepted rule of thumb.

\section{Results}

\section{Latent class analysis}

On the basis of the parental socialization variables of the total sample $(N=1120)$, we ran an LCA. Table 1 presents means and standard deviations for parent-child relationships scales, and the $z$-scores for each scale used to define the three classes. ${ }^{9}$

Class 1. Promotive relationship. This class comprised adolescents who presented high levels of attachment to parents $(-0.61)$, disclosure to parents $(0.52)$, and parental solicitation $(0.44)$, compared with the average of the total sample. The level of supervision was higher than that of the mean of the sample, although not significantly different. Regarding warmth, structure, and autonomy support, adolescents scored high on these measures $(0.69,0.54$, and 0.66 , respectively) and low on rejection, chaos, and coercion $(-0.63,-0.60$, and -0.36 , respectively). These $z$-scores indicate a combination of variables that suggests a promotive parent-child relationship.

Class 2. Detrimental relationship. Adolescents in this class indicated a low level of attachment to parents (1.72) and tended to not disclose a lot to their parents about their activities and whereabouts $(-1.20)$. These adolescents reported a lower level of parental solicitation $(-0.86)$ and parental supervision $(-0.47)$ than did others. They also reported a low level of parental warmth $(-1.97)$,

Table 1. Scales descriptives and $z$-scores for combinations of parent-child relationships (3-class) $(N=1120)$.

\begin{tabular}{lcccc}
\hline & Mean (SD) & Class 1 & Class 2 & Class 3 \\
\hline$N$ tot (1,120) (\%) & & $\mathbf{5 5 0}(49.11)$ & $\mathbf{9 5}(8.48)$ & $\mathbf{4 7 5}(42.41)$ \\
$n$ girls (591) (\%) & $293(49.6)$ & $61(10.3)$ & $237(40.1)$ \\
$n$ boys (529) (\%) & $257(48.6)$ & $34(6.4)$ & $238(45.0)$ \\
Parental attachment & $2.08(1.06)$ & $-\mathbf{0 . 6 1}$ & $\mathbf{1 . 7 5}$ & $\mathbf{0 . 3 7}$ \\
Child disclosure & $3.22(1.25)$ & $\mathbf{0 . 5 2}$ & $\mathbf{- 1 . 2 1}$ & $\mathbf{- 0 . 3 6}$ \\
Parental solicitation & $3.03(1.25)$ & $\mathbf{0 . 4 4}$ & $\mathbf{- 0 . 6 9}$ & $\mathbf{- 0 . 3 4}$ \\
Parental supervision & $3.91(1.24)$ & 0.23 & $\mathbf{- 0 . 4 7}$ & -0.18 \\
Warmth & $3.27(.74)$ & $\mathbf{0 . 6 9}$ & $\mathbf{- 1 . 9 7}$ & $\mathbf{- 0 . 4 1}$ \\
Rejection & $1.79(.87)$ & $-\mathbf{0 . 3 5}$ & $\mathbf{1 . 7 8}$ & $\mathbf{0 . 3 7}$ \\
Structure & $2.99(.79)$ & $\mathbf{0 . 5 4}$ & $\mathbf{- 1 . 5 0}$ & $\mathbf{- 0 . 3 3}$ \\
Chaos & $2.25(.93)$ & $-\mathbf{0 . 6 0}$ & $\mathbf{1 . 2 5}$ & $\mathbf{0 . 4 4}$ \\
Autonomy support & $3.22(.79)$ & $\mathbf{0 . 6 3}$ & $\mathbf{- 1 . 6 0}$ & $\mathbf{- 0 . 3 3}$ \\
Coercion & $2.22(.82)$ & $-\mathbf{0 . 3 6}$ & $\mathbf{1 . 2 0}$ & 0.18 \\
\hline
\end{tabular}

\footnotetext{
${ }^{8}$ Note that criminological studies often use offending as the dependent variable. In the context of the Situational Action Theory, the parental socialization process cannot directly explain offending. The socialization process is part of the developmental part of the SAT. Indeed, socialization agents are indirect causes of crimes.

${ }^{9}$ The scales used for LCA all are significantly correlated to each other (see Appendix, Table II). Although some correlations were rather high (e.g. .72 between warmth and autonomy support, or -.63 between rejection and autonomy support), multicollinearity was not a problem in our analyses, in which the VIF (variance inflation factor) scores were all well below 10 (the highest was 3.21) and the tolerance statistics all well above 0.2 , the commonly accepted rules of thumb.
} 
structure (-1.53), and autonomy support $(-1.90)$. This combination suggests that these adolescents had a detrimental parent-child relationship.

Class 3. Balanced relationship. This class comprised adolescents with a low level of parental attachment (0.37), but this attachment is neither good nor bad (mean of 2.45 [2.08 +0.37$]$ on a 5-point scale). These adolescents generally disclosed less information to their parents $(-0.34)$ and were less solicited $(-0.34)$ than the mean of adolescents. Results indicate moderate disclosure and parental solicitation. Parental supervision was lower but not significantly different from that of the mean. They also reported a lower level of parental warmth $(-0.41)$, structure $(-0.33)$, and autonomy support $(-0.38)$. Nevertheless, the general means of these 4 -point scales were high $(3.27,2.99$, and 3.22 , respectively), indicating that these adolescents tended to experience warmth, structure, and autonomy support in their family, but to a low degree. Finally, they reported higher levels of rejection (0.37) and chaos (0.44) than did the mean. These scores indicate that these adolescents oscillated between warmth and rejection, and also structure and chaos. These $z$-scores indicate a balanced combination, with a complex parent-child relationship, neither good nor bad. ${ }^{10}$

\section{Multinomial logistic regressions}

Table 2 presents the MLR model used to test combinations of parent-child relationships as determinants of moral values for boys and girls separately. The results indicate that the model reached statistical significance for both boys and girls (according to a likelihood ratio test, $p<.05$ ). We used detrimental parent-child relationship (Class 2$)$ as the reference category ( $\mathrm{B}=0$ in Table 2$)$ because this class differs the most from the two other latent classes.

Looking at the results for girls, the greater difference is between promotive (Class 1) and detrimental (Class 2). The girls with a promotive parent-child relationship had $2.38(1 / 0.42)$ times higher likelihood of having high rather than low moral values, compared with girls with a detrimental parent-child relationship $(\mathrm{B}=-0.86, S E=0.67, p=.20) .{ }^{11}$ In a more marginal way, girls with a promotive relationship also had a higher likelihood (1.76) of having medium rather than low moral values, compared with girls with a detrimental relationship $(\mathrm{B}=0.56, S E=0.42, p=.18$ ). Nevertheless, $p$ is higher than 0.05 , meaning that combinations of parent-child relationships do not significantly predict whether girls have low, medium, or high moral values.

Concerning boys, the greater difference is also between promotive and detrimental combinations. For example, boys with a promotive combination had 1.76 times higher likelihood of having medium rather than low moral values, compared with boys with a detrimental parent-child relationship ( $\mathrm{B}=0.57, \mathrm{~S} E=0.51, p=.26$ ). But because of nonsignificant results, the same conclusion can be made for boys as for girls: the combinations of parent-child relationships do not significantly predict the level of boys' moral values.

Contrary to combinations of parent-child relationship, school social bond significantly predicted whether boys and girls had low, medium, or high moral values. For example, odds ratios show that as girls had one more unit better bond to school, the change in the odds of having high rather than low morality was $1 / 0.19=5.26(\mathrm{~B}=-1.66, S E=0.33, p=.00)$. In short, they were more likely to have high moral values if they had a good bond to school. For boys, regarding the same predictor and the category high versus low, the effect size $(B=-1.38, S E=0.32, p=.00)$ and the odds ratio $(1 / 0.25=$

\footnotetext{
${ }^{10}$ The distribution into classes for adjudicated and nonadjudicated adolescents (see Appendix, Table IV) indicates a similar percentage of both groups in Class 3 (41.67\% and 42.50\%, respectively). For Class 1 and Class 2, distributions are different. There are proportionally less adjudicated adolescents belonging to Class 1 (39.17\%, vs. $50.30 \%$ for nonadjudicated), and more belonging to Class 2 (19.17\%, vs. $7.20 \%$ for nonadjudicated). Concerning the distribution of nonadjudicated boys and girls: this is almost the same for Class 1, while there are proportionally slightly more girls in Class 2 and more boys in Class 3 . Concerning adjudicated adolescents, while the distribution of boys and girls is proportionally nearly the same for Class 3, we notice proportionally twice as many boys (44.44\%) as girls (23.33\%) in Class 1 and three times more girls (36.67\%) than boys (13.33\%) in Class 2. Although some differences exist for the repartition, we did not find a specific combination for the subgroup of delinquent.

${ }^{11}$ Odds ratio coefficients indicate the probability that membership in one of these three classes will predict the level of morality (low, moderate, or high).
} 


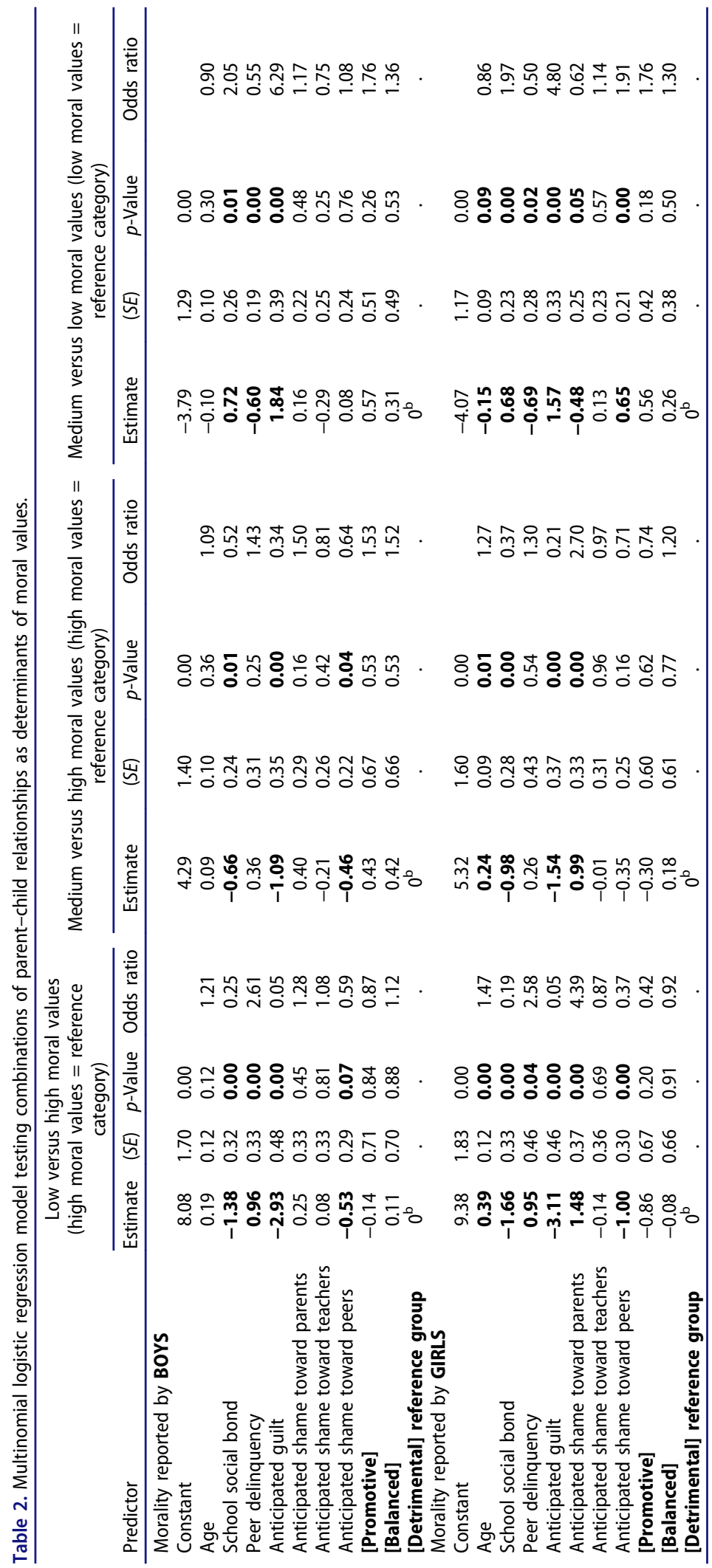


3.95) are lower, but the conclusion is the same. Exposure to peer delinquency also significantly predicted adolescents' level of moral values. For example, the results for girls indicate that as girls had one more unit delinquent friends, the change in the odds of having low rather than high morality was $2.58(\mathrm{~B}=0.95, S E=0.46, p=.04)$, and the change in the odds of having low rather than medium morality was $1 / 0.51=1.96(\mathrm{~B}=-0.69, S E=0.28, p=.02)$. But one unit increase in exposure to peer delinquency has no significant effect on the change in the odds of having medium rather than high morality. For boys, effect size and odds ratios are weaker, but conclusions are the same as for girls: boys were more likely to have low moral values than high or medium moral values if they had delinquent friends. Results indicate that effect size and odds ratios are higher for school social bond than for peer delinquency for both boys and girls. This indicates that, in general, school social bond is a stronger predictor of the level of moral values than is exposure to peer delinquency.

The results also indicate the effects of the moral emotions of anticipated shame and guilt on moral values. The odds ratios tell us that as adolescents had one more unit anticipated guilt, the change in the odds of having high rather than low moral values was $1 / .05=20$ for girls $(B=-3.11$, $S E=0.46, p=.00)$ and $1 / .05=20$ for boys $(B=-2.93, S E=0.48, p=.00),{ }^{12}$ meaning that in both groups, adolescents were more likely to have high rather than low moral values if they were able to anticipate feelings of guilt. Results indicate differences for anticipated shame, depending on the group (boys or girls) and depending on the significant other. For boys, anticipated shame toward parents and toward teachers are not significant predictors of the level of moral values. On the contrary, anticipated shame toward peers is a significant predictor in one situation: as boys had one more unit anticipated shame toward peers, the change in odds of having high rather than medium morality was $1 / 0.64=1.58$. For girls, as for boys, while anticipated shame toward teachers had no significant effect on moral values, anticipated shame toward parents had a significant effect. The odds ratios tell us that as girls felt one more unit of anticipated shame toward their parents, the change in odds of having low rather than high moral values was $4.39(\mathrm{~B}=1.48, S E=0.38, p=.00)$ and medium rather than high moral values was $2.70(\mathrm{~B}=0.99, S E=0.33, p=.00)$. Concerning anticipated shame toward peers, as girls felt one more unit of anticipated shame toward their peers, the change in odds of having high rather than low moral values is $1 / 0.37=2.70(\mathrm{~B}=-1.00, S E=0.30, p=.00)$. Contrary to anticipated shame toward parents that predicted low moral values versus high, anticipated shame toward peers predicted high moral values versus low. Results for anticipated shame toward peers as predictors of moral values are comparable for boys and girls. On the contrary, anticipated shame toward parents is significant for girls and not for boys, despite a similar direction of effects. The sense of the effects of anticipated shame toward teachers is less consistent and never significant.

Age is a significant predictor for girls when comparing low versus high moral values, and medium versus high moral values. In the first situation, for example, the odds ratio tells us that as girls had one more unit of age, the change in the odds of having high rather than low moral values was 1.47 ( $B$ $=0.39, S E=0.12, p=.00)$. In short, they are more likely to have low moral values if they are older.

\section{Discussion}

The results of this study suggest that socialization agents, such as parents, school, and peers, play an important role in the development of moral values (Wikström and Sampson 2003), the lack of which is thought to be the main cause of crime (Wikström 2010). Previous studies have argued that successful socialization processes lead to the internalization of moral values, which in turn leads individuals to feel anticipatively ashamed and guilty when they consider offending. Unfortunately, it is rare for criminological inquiries to extensively investigate socialization agents. In response, this study sought to more deeply investigate parents as the main and first socialization agent, and to explore the relationships of the three most important socialization agents during adolescence -

\footnotetext{
${ }^{12}$ Numbers have been rounded, which explains similar odds ratios for boys and girls, but different effect sizes.
} 
parents, school, and peers - and anticipated moral emotions as predictors of moral values. We formulated four hypotheses.

First, we expected to find different combinations of parent-child relationships and expected that these combinations would be differently associated with moral values. Our findings revealed three combinations: promotive, detrimental, and balanced, indicating that parent-child relationships are more complex than a binary perspective of good or bad parenting. The six dimensions of parenting posited by Skinner, Johnson, and Snyder (2005) enabled us to nuance the traditional approach to investigating the parent-child bond and understand this social bond more deeply. On the basis of the three combinations, we investigated moral values as the dependent variable. Results indicate that ascribing to one of the three combinations does not predict the level of moral values. The average age of our sample (15.8 years) could be an explanatory element. As children grow, the importance of secondary socialization agents, such as school and peers, increases (Sheikh and Janoff-Bulman 2010; Weerman 2004). As such, the development of an individual's morality is not limited to childhood. It evolves and changes with time and the influence of different socialization agents (Wikström 2005).

Second, we hypothesized that anticipated shame (toward parents, school, and peers) and anticipated guilt positively predict high moral values. Our results indicate that anticipated guilt is the most influential anticipated moral emotion for predicting moral values. These findings are in line with recent studies that have argued that anticipated guilt has a higher predictive power of criminal offending than does anticipated shame (e.g. Pauwels and Svensson 2015) because guilt springs from the integration of high moral values and prevents an individual from seeing the crime in a favorable light. Further, our findings show contrasted results for anticipated shame, depending on the significant other. While anticipated shame toward teachers is not significant for predicting moral values for girls nor for boys, anticipated shame toward peers is significant for predicting moral values for both groups: to anticipate feeling ashamed toward peers in the event of a rule-breaking act predicts higher moral values. This result highlights the degree to which attachment to peers at this age shapes the impact that peers have on adolescents' moral values (higher than the impact of parents or school). Because they have integrated the prosocial moral values that they share with peers, adolescents anticipate feelings of shame toward their friends when they consider a rulebreaking act. Contrary to anticipated shame toward peers, anticipated shame toward parents predicted low moral values (versus high), and this result was only significant for girls. In other words, girls who do not feel anticipatively ashamed toward parents have higher moral values. This result contradicts the assumption of a positive relation between anticipated shame and moral values and should be further investigated. According to some researchers, genetic and environmental factors may explain differences in boys and girls in terms of moral emotions (Tangney and Dearing 2002); that is, both boys and girls can feel ashamed, but the type of situation explains the differences in feeling (e.g. Benetti-McQuoid and Bursik 2005; Manion 2003). These differences are linked to the different social roles attributed to boys and to girls. According to Chaplin (2015), more social expectations are placed on girls, causing them to blame themselves for their failures more readily than do boys (Lewis, Haviland-Jones, and Barrett 2008), which can explain the differences in the effects' size. Splitting the anticipated shame concept enabled us to identify more nuance in the impact of anticipated emotion on moral values and to discover unexpected relations, contrary to studies that use only one dimension for anticipated shame.

Third, we assumed that school social bond and exposure to peer delinquency would predict moral values; that is, a higher attachment to school predicts higher conventional moral values, and the higher one's level of exposure to peer delinquency, the less likely they are to adhere to moral values. Findings indicate support for this hypothesis for both boys and girls. While combinations of parentchild relationships did not show a significant effect on moral values, the two other socialization agents displayed a significant effect. These findings align with studies that have shown that adolescence is a time of increasing impact of secondary socialization agents on adolescents' moral values that confirm or change those values (Sheikh and Janoff-Bulman 2010; Weerman 2004). Our 
results also align with those of Svensson, Pauwels, and Weerman (2017a), whose findings confirmed that attachment to school and peers affects moral values.

Fourth, we expected that, although effect size may be different for boys and girls, previous hypotheses apply to both. Our results show that even though age seems to have a significant impact on girls' level of moral values that anticipated shame toward parents is a significant predictor for this group, and that despite different effect size, mechanisms appear to be similar for both boys and for girls: combinations do not significantly predict the level of moral values, school social bond and peer delinquency are two significant predictors of the level of moral values and act in the same direction, anticipated guilt is the most significant predictor of the level of moral values, and anticipated shame toward school and peers does not have a significant impact on their moral values. These results are in line with theories and studies arguing that common factors can explain involvement in crime by both boys and girls (De Coster, Heimer, and Cumley 2013; Ivert et al. 2018; Meier 2010; Moffitt et al. 2001). Moffitt et al. (2001) indicate that risk factors for delinquent behavior are more similar than different for both genders. Although we do not adopt a "risk factors" approach and mentioned the necessary need to take an integrated criminological framework into account that emphasizes "mechanisms" (what risk factors' approaches do not), our results are in line with the perspective of Moffitt et al. (2001). According to Wikström et al. (2012), what explains the gender gap in crime involvement is not different factors but differences on these factors (Hirtenlehner and Treiber 2017; Weerman et al. 2016).

\section{Study limitations}

Some limitations in this study should be taken into account. First, this study has a cross-sectional design. Moral values and anticipated moral emotions, but also socialization variables, are measured at one point in time. Our results showing that the level of moral values is not significantly dependent on parent-child relationships could be associated with the age of the adolescents. In other words, the same study on younger adolescents, or even children, could reveal significant results. Furthermore, a cross-sectional design does not demonstrate causality. Our assumptions concerning the "direction of the relationship" (i.e. whether variables are dependent or independent) are based on theory. Our results cannot prove it. Longitudinal studies could address this limitation and evaluate changes over time in the impact of socialization agents on individuals' morality. Second, although this study used LCA, which enabled a deeper investigation of parental socialization, combinations should be further investigated, especially the "balanced" combination. The complexity within families could partly explain the "balanced" combination. For example, questions were asked regarding "parents" without distinguishing between both (biological) parents, with whom relationships could be totally different. Furthermore, youth may have adoptive parents, or stepparents, or other parental figures, making it even more difficult to answer questions. Therefore, further investigation is needed. Third, although this study emphasizes how important it is to investigate the parent-child social bond more profoundly, further studies are needed to increase our understanding of other social bonds as well, particularly those with school and peers, to bring to light their complexity and contribute to the understanding of juvenile delinquency. Fourth, although a sample with a maximal heterogeneity was necessary, the combination of a community-based subsample and a delinquent subsample implies methodological precautions given the different nature of both subsamples. The methodological implications of such a combination need to be investigated. Finally, this study does not take into account biological markers in the explanation of moral values. Thus, it remains possible that some statistical effects are confounded (Sariaslan et al. 2013).

Despite these limitations, this study used a large and heterogeneous sample to help reveal the complexity between socialization agents, moral emotions, and moral values. It also suggests a way to better understand and operationalize social bonds, which is necessary to capture the complexity of socialization processes and their influence on individuals' morality (moral values and moral emotions). This study suggests that no significant relationship exists between combinations of parent-child relationships and moral values, indicating that other socialization agents (school and peers) may have 
a greater impact on adolescents' moral values. Although it lends nuance to the impact of parental bond on adolescents' moral values, our study is in line with the bioecological model of Bronfenbrenner (Bronfenbrenner and Ceci 1994; Bronfenbrenner and Morris 2006), which argues that children evolve in different social environments that influence each other, and together they form a moral context. The influence of these socialization agents evolves as children get older and school and peers become more important. Our study is also in line with the main premise of SAT, that social bonds are the cause of moral values and moral emotions (Wikström 2010). According to SAT, individuals with high moral values will not see crime as an acceptable action when they are confronted by a situation that tempts them to commit a crime. Nevertheless, our study lends nuance to the role of anticipated shame and anticipated guilt in explaining moral values. While anticipated guilt is an important predictor of moral values, anticipated shame is inconsistent, depending on the significant other. Braithwaite (1989) argued that a key to successful crime prevention is to make offenders ashamed about what they have done, in order to decrease future offending, and indeed, shame has long been considered the most painful moral emotion (Tangney and Dearing 2002). Our study seems to suggest that from the perspective of crime prevention, offenders' anticipated feelings of guilt may be more critical than anticipated feelings of shame. Further research is needed to investigate the inconsistency of anticipated shame and enhance the understanding of the complex and probably bidirectional relationships between moral values and moral emotions. Further panel studies are necessary to capture the within-individual-level changes in moral values and moral emotions and the impact of socialization agents at different stages in the life course.

\section{Notes on contributors}

Julie Grégoire is Doctor of criminology, Scientific Collaborator at Liège University, Faculty of Law, Political Science, and Criminology (Belgium) and member of the Center-Research-Intervention-Youth. She is interested in juvenile delinquency, juveniles in custody, integrated theories, and quantitative and qualitative methods.

Lieven J.R. Pauwels is Professor of Criminology at Ghent University, Faculty of Law and Criminology (Belgium). He is Head of the Institute for International Research on Criminal Policy (IRCP). He is interested in theories of crime causation, theoretical integration, the philosophy of science and causation, and quantitative methods.

\section{References}

Agnew, Robert and Helene R. White. 1992. “An Empirical Test of General Strain Theory.” Criminology 30 (4):475-500. doi:10.1111/j.1745-9125.1992.tb01113.x.

Akers, Ronald L. 1985. Deviant Behavior. A Social Learning Approach. Belmont, CA: Wadsworth Publishing.

Akers, Ronald L. 1998. Social Learning and Social Structure: A General Theory of Crime and Deviance. Boston, MA: Northeastern University Press.

Akers, Ronald L. 2017. Social Learning and Social Structure: A General Theory of Crime and Deviance. New York: Routledge.

Baumeister, Roy F., Arlene M. Stillwell, and Todd F. Heatherton. 1994. "Guilt: An Interpersonal Approach." Psychological Bulletin 115 (2):243-67. doi:10.1037/0033-2909.115.2.243.

Benetti-McQuoid, Jessica and Krisanne Bursik. 2005. "Individual Differences in Experiences of and Responses to Guilt and Shame: Examining the Lenses of Gender and Gender Role.” Sex Roles 53 (102):133-42. doi:10.1007/ s11199-005-4287-4.

Blokland, Arjan and Van Os. Rianne. 2010. "Life Span Offending Trajectories of Convicted Dutch Women." International Criminal Justice Review 20 (2):169-87. doi:10.1177/1057567710368938.

Bowlby, John. 1982. "Attachment and Loss: Retrospect and Prospect." The American Journal of Orthopsychiatry 52 (4):664-78. doi:10.1111/j.1939-0025.1982.tb01456.x.

Braithwaite, John. 1989. Crime, Shame and Reintegration. Cambridge, UK: Cambridge University Press.

Bronfenbrenner, Urie. 1979. The Ecology of Human Development. Cambridge, MA: Harvard University Press.

Bronfenbrenner, Urie and Pamela A. Morris. 2006. “The Bioecological Model of Human Development." Pp. 739-828. in Handbook of Child Psychology, Vol. 1, Theoretical Models of Human Development, $6^{\text {th }}$ ed., edited by W. Damon and R. M. Lerner. Wiley: New York.

Bronfenbrenner, Urie and Stephen J. Ceci. 1994. "Nature-Nurture Reconceptualized in Developmental Perspective: A Bioecological Model.” Psychological Review 101 (4):568-86. doi:10.1037/0033-295X.101.4.568. 
Chaplin, T M. 2015. “Gender and Emotion Expression: A Developmental Contextual Perspective." Emotion Review : Journal of the International Society for Research on Emotion 7 (1):14-21. doi:10.1177/1754073914544408.

Colvin, Mark. 2000. Crime and Coercion: An Integrated Theory of Chronic Criminality. New York: Springer.

Colvin, Mark, Francis T. Cullen, and Thomas Vander Ven. 2002. "Coercion, Social Support, and Crime: An Emerging Theoretical Consensus.” Criminology 40 (1):19-42. doi:10.1111/j.1745-9125.2002.tb00948.x.

Cullen, Francis T. 1994. "Social Support as an Organizing Concept for Criminology: Presidential Address to the Academy of Criminal Justice Sciences.” Justice Quarterly 11 (4):527-59. doi:10.1080/07418829400092421.

De Boeck, Arne, Stefaan Pleysier, and Johan Put. 2017. "The Social Origins of Gender Differences in Anticipated Feelings of Guilt and Shame following Delinquency.” Criminology \& Criminal Justice 18 (3):291-313. doi:0.1177/ 1748895817721273.

De Coster, Stacy, Karen Heimer, and Samantha R. Cumley. 2013. ““Gender and Theories of Delinquency.” Pp. 313-32 in The Oxford Handbook of Criminological Theory, edited by F. T. Cullen and P. Wilcox. New York: Oxford University Press,

Elias, Maurice J., Sarah J. Parker, V. Megan Kash, Roger P. Weissberg, and Mary Utne O’Brien. 2008. “Social and Emotional Learning, Moral Education, and Character Education: A Comparative Analysis and A View toward Convergence." Pp. 248-66 in Handbook of Moral and Character Education, edited by L. P. Nucci and D. Narvaez. New York: Routledge,

Elster, Jon. 1999. Alchemies of the Mind: Rationality and the Emotions. Cambridge, UK: Cambridge University Press.

Fontaine, Nathalie, René Carbonneau, Edward D. Barker Frank Vitaro, and Richard E. Tremblay. 2009. "Research Review: A Critical Review of Studies on the Developmental Trajectories of Antisocial Behavior in Females." Journal of Child Psychology and Psychiatry 50 (4):363-85. doi:10.1111/j.1469-7610.2008.01949.x.

Gecas, Viktor. 2000. “Socialization.” Pp. 2855-64. in Encyclopedia of Sociology, Vol. 4:2nd edited by, E. F. Borgatta and R. J. V. Montgomery. New York: Macmillan Reference.

Gecas, Viktor. 2001. “The Self as a Social Force.” Pp. 85-100 in Extending Self-Esteem Theory and Research: Sociological and Psychological Currents, edited by T. J. Owens, S. Stryker, N. Goodman. Cambridge, UK: Cambridge University Press

Gorman-Smith, Deborah, Patrick H. Tolan, and David B. Henry. 1999. "The Relation of Community and Family to Risk among Urban-Poor Adolescents.” Pp. 349-67 in Historical and Geographical Influences on Psychopathology, edited by P. Cohen, C. Slomkowski, Lee N. Robins. Mahwah, NJ: Lawrence Erlbaum

Grusec, Joan E. 2011. "Socialization Processes in the Family: Social and Emotional Development." Annual Review of Psychology 62:243-69. doi:10.1146/annurev.psych.121208.131650.

Hardy, Sam A., Laura M. Padilla-Walker, and Gustavo Carlo. 2008. "Parenting Dimensions and Adolescents' Internalisation of Moral Values.” Journal of Moral Education 37 (2):205-23. doi:10.1080/03057240802009512.

Hart, Daniel and Gustavo Carlo. 2005. "Moral Development in Adolescence." Journal of Research on Adolescence 15 (3):223-33. doi:10.1111/j.1532-7795.2005.00094.x.

Hinkle, Dennis E., William Wiersma, and Stephen G. Jurs. 2003. Applied Statistics for the Behavioral Sciences. Boston, MA: Houghton Mifflin.

Hirschi, Travis. 1969. Causes of Delinquency. Berkeley: University of California Press.

Hirtenlehner, Helmut and Kyle Treiber. 2017. "Can Situational Action Theory Explain the Gender Gap in Adolescent Shoplifting? Results from Austria.” International Criminal Justice Review 27 (3):165-87. doi:10.1177/ 1057567717690199.

Hoeve, Machteld, Judith S. Dubas, Veroni I. Eichelsheim, Peter H. Van der Laan, Wilma Smeenk, and R.M. Gerris Jan. 2009. "The Relationship between Parenting and Delinquency: A Meta-Analysis." Journal of Abnormal Child Psychology 37 (6):749-75. doi:10.1007/s10802-009-9310-8.

Horn, Stacey S., Christopher Daddis, and Melanie Killen. 2008. "Peer Relationships and Social Groups: Implications for Moral Education." Pp. 267-87 in Handbook of Moral and Character Education, edited by L. P. Nucci and D. Narvaez. New York: Routledge,

Huizinga, David, Finn-Aage Esbensen, and Anne Wylie Weiher. 1991. "Are There Multiple Paths to Delinquency." The Journal of Criminal Law and Criminology (1973-) 82:83-118. doi:10.2307/1143790.

Ivert, Anna-Karin, Frida K. Andersson, Lieven J. Pauwels Robert Svensson, and Marie Torstensson Levander. 2018. "An Examination of the Interaction between Morality and Self-Control in Offending: A Study of Differences between Girls and Boys." Criminal Behaviour and Mental Health 28:282-94. doi:10.1002/cbm.2065.

Jennings, Wesley G., Mildred M. Maldonado-Molina, Alex R. Piquero, Candace L. Odgers, Hector Bird, and Glorisa Canino. 2010. "Sex Differences in Trajectories of Offending among Puerto Rican Youth." Crime \& Delinquency 56 (3):327-57. doi:10.1177/0011128710372478.

Kim, Su Yeong, Yijie Wang, Diana Orozco-Lapray, Yshan Shen, and Mohammed Murtuza. 2013. "Does "Tiger Parenting" Exist? Parenting Combinations of Chinese Americans and Adolescent Developmental Outcomes.." Asian American Journal of Psychology 4 (1):7-18. doi:10.1037/a0030612.

Krebs, Dennis. 2011. The Origins of Morality: An Evolutionary Account. New York: Oxford University Press. 
Lanctôt, Nadine, Annie Lemieux, and Cécile Mathys. 2016. "The Value of a Safe, Connected Social Climate for Adolescent Girls in Residential Care." Residential Treatment for Children \& Youth 33 (3-4):247-69. doi:10.1080/ 0886571X.2016.1207218.

Lewis, Michael. 1992. Shame. The Exposed Self. New York: Free Press.

Lewis, Michael, Jeanette M. Haviland-Jones, and Lisa Feldman Barrett. 2008. Handbook of Emotions. New York: Guilford Press.

Loeber, Rolf and Magda Stouthamer-Loeber. 1986. "Family Factors as Correlates and Predictors of Juvenile Conduct Problems and Delinquency." Crime and Justice 7:129-49. doi:10.1086/449112.

Lucia, Sonia, Leslie Herrmann, and Martin Killias. 2007. "How Important are Interview Methods and Questionnaire Designs in Research on Self-Reported Juvenile Delinquency? an Experimental Comparison of Internet Vs Paper-And-Pencil Questionnaires and Different Definitions of the Reference Period." Journal of Experimental Criminology 3 (1):39-64. doi:10.1007/s11292-007-9025-1.

Luyckx, Koen, Elizabeth A. Tildesley, Judy A. Bart Soenens, Sara E. Andrews, Missy Peterson Hampson, and Bart Duriez. 2011. "Parenting and Trajectories of Children's Maladaptive Behaviors: A 12-Year Prospective Community Study." Journal of Clinical Child \& Adolescent Psychology 40 (3):468-78. doi:10.1080/ 15374416.2011.563470.

Malti, Tina, Nancy Eisenberg, Hyunji Kim, and Marlis Buchmann. 2013. "Developmental Trajectories of Sympathy, Moral Emotion Attributions, and Moral Reasoning: The Role of Parental Support." Social Development 22 (4):773-93. doi:10.1111/sode.12031.

Manion, Jennifer C. 2003. "Girls Blush, Sometimes: Gender, Moral Agency, and the Problem of Shame." Hypatia 18 (3):21-41. doi:10.1111/j.1527-2001.2003.tb00820.x.

Marsee, Monica A. and Paul J. Frick. 2007. "Exploring the Cognitive and Emotional Correlates to Proactive and Reactive Aggression in a Sample of Detained Girls." Journal of Abnormal Child Psychology 35 (6):969-81. doi:0.1007/s10802-007-9147-y.

Mazerolle, Paul and Alex R. Piquero. 1997. "Violent Responses to Strain: An Examination of Conditioning Influences." Violence and Victims 12 (4):323-43. doi:10.1891/0886-6708.12.4.323.

McCord, Joan. 1986. "Instigation and Insulation: How Families Affect Antisocial Aggression." Pp. 343-57 in Development of Antisocial and Prosocial Behavior, edited by D. Olweus, J. Block, and M. Radke-Yarrow. New York: Academic Press,

Meier, Madeline H. 2010. "Sex Differences in Antisocial Behavior." Ph.D. dissertation, University of Missouri, Columbia.

Moffitt, Terrie E., Avsholam Caspi, Michael Rutter, and Phil A. Silva. 2001. Sex Differences in Antisocial Behaviour: Conduct Disorder, Delinquency, and Violence in the Dunedin Longitudinal Study. Cambridge, UK: Cambridge University Press.

Muthén, Bengt and Linda K. Muthén. 2000. "Integrating Person-Centered and Variable-Centered Analyses: Growth Mixture Modeling with Latent Trajectory Classes." Alcoholism: Clinical and Experimental Research 24 (6):882-91. doi:10.1111/j.1530-0277.2000.tb02070.x.

Nelson, Larry J., Laura M. Padilla-Walker, Katherine J. Christensen, Cortney A. Evans, and Jason S. Carroll. 2011. "Parenting in Emerging Adulthood: An Examination of Parenting Clusters and Correlates." Journal of Youth and Adolescence 40 (6):730-43. doi:10.1007/s10964-010-9584-8.

Nylund, Karen L., Tihomir Asparouhov, and Bengt O. Muthén. 2007. "Deciding on the Number of Classes in Latent Class Analysis and Growth Mixture Modeling: A Monte Carlo Simulation Study." Structural Equation Modeling 14 (4):535-69. doi:10.1080/10705510701575396.

Opp, Karl-Dieter and Lieven J. Pauwels. 2018. "Die Theorie Rationalen Handelns Als Grundlage Einer Analytischen Kriminologie" [The rational action theory as the basis of an analytical criminology]. Monatsschrift für Kriminologie und Strafrechtsreform 101(3-4):223-50. Retrieved March 5, 2019. (https://www.researchgate.net/publication/ 331176060_Die_weite_Version_der_Theorie_rationalen_Handelns_als_Grundlage_einer_Analytischen_ Kriminologie_The_Theory_of_Rational_Action_as_a_Foundation_of_an_Analytical_Criminology).

Pardini, Dustin A., Paula J. Fite, and Jeffrey D. Burke. 2008. "Bidirectional Associations between Parenting Practices and Conduct Problems in Boys from Childhood to Adolescence: The Moderating Effect of Age and African-American Ethnicity." Journal of Abnormal Child Psychology 36 (5):647-62. doi:10.1007/s10802-007-9162-z.

Parker, Jennifer S. and Mark J. Benson. 2004. "Parent-Adolescent Relations and Adolescent Functioning: Self-Esteem, Substance Abuse, and Delinquency." Adolescence 39(155):519-30. Retrieved April 14, 2018 https://www.ncbi.nlm. nih.gov/pubmed/15673227

Pauwels, Lieven J. and Robert Svensson. 2010. "Informal Controls and the Explanation of Propensity to Offend: A Test in Two Urban Samples.” European Journal on Criminal Policy and Research 16 (1):15-27. doi:10.1007/ s10610-009-9115-x.

Pauwels, Lieven J. and Robert Svensson. 2015. "Schools and Child Antisocial Behavior: In Search for Mediator Effects of School-Level Disadvantage.” SAGE Open 5 (2):1-13. doi:10.1177/2158244015592936.

Pinker, Steven. 2004. The Blank Slate: The Modern Denial of Human Nature. New York: Viking. 
Piquero, Alex R. and Robert W. Brame. 2008. "Assessing the Race-Crime and Ethnicity-Crime Relationship in a Sample of Serious Adolescent Delinquents." Crime \& Delinquency 54 (3):390-422. doi:10.1177/ 0011128707307219.

Rebellon, Cesar J., Nicole Leeper Piquero, Alex R. Piquero, and Stephen G. Tibbetts. 2010. “Anticipated Shaming and Criminal Offending.” Journal of Criminal Justice 38 (5):988-97. doi:10.1016/j.jcrimjus.2010.06.016.

Reckless, Walter C. 1967. The Crime Problem. New York: Appleton-Century-Crofts.

Remacle, C., A. Jaspart, and D. De Fraene. 2012. Des Jeunes En IPPJ. Des Regards Sur La Vie À La Recherche De Trajectoires. Rapport De Recherche Sur Les Parcours De Vie Des Jeunes Placés En IPPJ [Looks on Life Searching for Pathways. Research Report on the Life-Course of Young People Institutionalized in IPPJ]. Brussels: Belgium: ULB. Retrieved March 19, 2018 (http://www.huytebroeck.be/IMG/pdf/Rapport_final_CRC_Trajectoires.pdf).

Rosenbaum, Alan, Mandy M. Rabenhorst, Madhavi K. Reddy, Matthew T. Fleming, and Nicolette L. Howells. 2006. “A Comparison of Methods for Collecting Self-Report Data on Sensitive Topics." Violence and Victims 21 (4):461-71. doi:10.1891/0886-6708.21.4.461.

Sampson, Robert J. and John H. Laub. 1993. Crime in the Making: Pathways and Turning Points through Life. Cambridge, MA: Harvard University Press.

Sariaslan, Amir, Niklas Långström, Brian D’ Onofrio, Johan Hallqvist, Johan Franck, and Paul Lichtenstein. 2013. “The Impact of Neighbourhood Deprivation on Adolescent Violent Criminality and Substance Misuse: A Longitudinal, Quasi-Experimental Study of the Total Swedish Population.” International Journal of Epidemiology 42 (4):1057-66. doi:10.1093/ije/dyt066.

Scheff, Thomas J. 1997. Emotions, the Social Bond, and Human Reality: Part/Whole Analysis. Cambridge, UK: Cambridge University Press.

Sheikh, Sana and Ronnie Janoff-Bulman. 2010. "Tracing the Self-Regulatory Bases of Moral Emotions." Emotion Review 2 (4):386-96. doi:10.1177/1754073910374660.

Skinner, Ellen, Sandy Johnson, and Tatiana Snyder. 2005. "Six Dimensions of Parenting: A Motivational Model." Parenting: Science and Practice 5 (2):175-235. doi:10.1207/s15327922par0502_3.

Stattin, Häkan and Margaret Kerr. 2000. "Parental Monitoring: A Reinterpretation.” Child Development 71 (4):1072 -85. doi:10.1111/1467-8624.00210.

Steinberg, Laurence. 2001. "We Know Some Things: Parent-Adolescent Relationships in Retrospect and Prospect." Journal of Research on Adolescence 11 (1):1-19. doi:10.1111/1532-7795.00001.

Steinberg, Lawrence and Jennifer S. Silk. 2002 "Parenting Adolescents." Pp. 103-33 in Handbook of Parenting, Vol. 1, edited by M. H. Bornstein. Mahwah, NJ: Lawrence Erlbaum.

Sutherland, Edwin H. 1947. Principles of Criminology. Philadelphia, PA: J.B. Lippincott.

Svensson, Robert. 2004. "Shame as A Consequence of the Parent-Child Relationship: A Study of Gender Differences in Juvenile Delinquency.” European Journal of Criminology 1 (4):477-504. doi:10.1177/1477370804045692.

Svensson, Robert, Frank M. Weerman, Lieven J. Pauwels, J. N. Bruinsma Gerben, and Wim Bernasco. 2013. "Moral Emotions and Offending: Do Feelings of Anticipated Shame and Guilt Mediate the Effect of Socialization on Offending?" European Journal of Criminology 10 (1):22-39. doi:10.1177/1477370812454393.

Svensson, Robert, Lieven J. Pauwels, and Frank M. Weerman. 2010. "Does the Effect of Self-Control on Adolescent Offending Vary by Level of Morality? A Test in Three Countries.” Criminal Justice and Behavior 37 (6):732-43. doi:10.1177/0093854810366542.

Svensson, Robert, Lieven J. Pauwels, and Frank M. Weerman. 2017a. "The Role of Moral Beliefs, Shame, and Guilt in Criminal Decision Making." Pp. 228-45 in The Oxford Handbook of Offender Decision Making, edited by W. Bernasco, H. Elffers, and J.-L. van Gelder. New York: Oxford University Press,

Svensson, Robert, Lieven J. Pauwels, Frank M. Weerman, J. N. Gerben and Bruinsma. 2017b. "Explaining Individual Changes in Moral Values and Moral Emotions among Adolescent Boys and Girls: A Fixed-effects Analysis." European Journal of Criminology 14 (3):290-308. doi: 10.1177/1477370816649626.

Tangney, June P., Jeff Stuewig, and Debra J. Mashek. 2007. "Moral Emotions and Moral Behavior." Annual Review of Psychology 58:345-72. doi:10.1146/annurev.psych.56.091103.070145.

Tangney, June P. and Ronda L. Dearing. 2002. Shame and Guilt: Emotions and Social Behavior. New York: Guilford Press.

Tanner-Smith, Emily E ., Sandra J. Wilson, and Mark W. Lipsey. 2013. “The Comparative Effectiveness of Outpatient Treatment for Adolescent Substance Abuse: A Meta-analysis.” Journal of Substance Abuse Treatment 44 (2):145-58. doi: 10.1016/j.jsat.2012.05.006.

Tibbetts, Stephen G. 2003. "Self-Conscious Emotions and Criminal Offending." Psychological Reports 93 (1):101-26. doi:10.2466/pr0.2003.93.1.101.

Tibbetts, Stephen G. and David L. Myers. 1999. "Low Self-Control, Rational Choice, and Student Test Cheating." American Journal of Criminal Justice 23(2):179-200. Retrieved April 10, 2018 http://www.academia.edu/download/ 46025357/bf0288727120160528-26780-1wzpu88.pdf doi:10.1007/BF02887271

Tomasello, Michael. 2016. A Natural History of Human Morality. Cambridge, MA: Harvard University Press. 
Weerman, Frank M. 1998. Het Belang Van Bindingen. "De Bindingstheorie Als Verklaring Van Verschillen En Veranderingen in Delinquent Gedrag" [The Bonding Theory as an Explanation of Differences and Changes in Delinquent Behavior]. Ph.D. dissertation, University of Groningen, The Netherlands.

Weerman, Frank M. 2004. "The Changing Role of Delinquent Peers in Childhood and Adolescence: Issues, Findings and Puzzles." Pp. 279-97 in Punishment, Places and Perpetrators: Developments in Criminology and Criminal Justice Research, edited by G. Bruinsma, H. Elffers, and J. De Keijser. Cullompton, UK: Willan Publishing,

Weerman, Frank M., Gerben J. Wim Bernasco, N. Bruinsma, and Lieven J. Pauwels. 2016. "Gender Differences in Delinquency and Situational Action Theory: A Partial Test.” Justice Quarterly 33 (7):1182-209. doi:10.1080/ 07418825.2015.1064987.

Wikström, Per-Olof H. and Robert J. Sampson. 2003. "Social Mechanisms of Community Influences on Crime and Pathways in Criminality." Pp. 118-48 in Causes of Conduct Disorder and Juvenile Delinquency, edited by B. B. Lahey, T. E. Moffitt, and A. Caspi. New York: Guilford Press,

Wikström, Per-Olof H. 2005. “The Social Origins of Pathways in Crime: Towards a Developmental Ecological Action Theory of Crime Involvement and Its Changes.” Pp. 211-45 in Integrated Developmental and Life-Course Theories of Offending, edited by D. P. Farrington. New York: Routledge,

Wikström, Per-Olof H. 2007. “"In Search of Causes and Explanations of Crime.” Pp. 117-39. in Doing Research on Crime and Justice, $2^{\text {nd }}$ ed., edited by R. D. King and E. Wincup. New York: Oxford University Press.

Wikström, Per-Olof H. 2010. “"Explaining Crime as Moral Actions.” Pp. 211-39 in Handbook of the Sociology of Morality, edited by S. Hitlin and S. Vaisey. New York: Springer,

Wikström, Per-Olof H. 2017. "Character, Circumstances and the Causes of Crime. Towards an Analytical Criminology." Pp. 501-21. in The Oxford Handbook of Criminology, $6^{\text {th }}$ ed., edited by A. Liebling, S. Maruna, and L. McAra. New York: Oxford University Press.

Wikström, Per-Olof H., Dietrich Oberwittler, Kyle Treiber, and Beth Hardie. 2012. Breaking Rules: The Social and Situational Dynamics of Young People's Urban Crime. New York: Oxford University Press.

Wikström, Per-Olof H. and Kyle Treiber. 2007. "The Role of Self-Control in Crime Causation: Beyond Gottfredson and Hirschi's General Theory of Crime." European Journal of Criminology 4 (2):237-64. doi:10.1177/ 1477370807074858 .

Wikström, Per-Olof H. and Robert Svensson. 2008. "Why are English Youths More Violent than Swedish Youths? A Comparative Study of the Role of Crime Propensity, Lifestyles and Their Interactions in Two Cities." European Journal of Criminology 5 (3):309-30. doi:10.1177/1477370808090835. 


\section{APPENDIX}

Table I. Descriptive statistics relating to scales used in latent class analysis $(N=1120)$.

\begin{tabular}{|c|c|c|c|}
\hline Construct & $a$ & Mean & $S D$ \\
\hline $\begin{array}{l}\text { Parental attachment } \\
\text { from "totally agree" (1) to "totally disagree" (5) }\end{array}$ & .79 & 2.08 & 1.06 \\
\hline You get along with your parents & & 1.76 & .91 \\
\hline Remarks of your parents are important & & 1.95 & .97 \\
\hline You like to spend free time with your parents & & 1.93 & .98 \\
\hline You talk with your parents if you have a problem & & 2.69 & 1.34 \\
\hline Child disclosure & .80 & 3.22 & 1.25 \\
\hline from "never" (1) to "always" (5) & & & \\
\hline You spontaneously tell your parents about your friends & & 3.22 & 1.22 \\
\hline You want to tell your parents about school & & 2.92 & 1.24 \\
\hline You keep a lot of secrets from your parents about what you do during your free time (reverse coded) & & 3.13 & 1.29 \\
\hline You hide a lot from your parents about what you do during nights and weekends (reverse coded) & & 3.96 & 1.21 \\
\hline You like to tell your parents about what you did and where you went during the evening & & 2.88 & 1.30 \\
\hline $\begin{array}{l}\text { Parental solicitation } \\
\text { from "never" (1) to "always" (5) }\end{array}$ & .72 & 3.03 & 1.25 \\
\hline Your parents talk with your friends when they come over to your house & & 3.78 & 1.14 \\
\hline Your parents ask you about what happened during your free time & & 3.51 & 1.16 \\
\hline Your parents have initiated a conversation with you about your free time (during the past month) & & 2.45 & 1.37 \\
\hline $\begin{array}{l}\text { Your parents have extra time to sit down and listen to you when you talk about what happened during } \\
\text { your free time }\end{array}$ & & 2.74 & 1.28 \\
\hline Your parents ask you to sit and tell them what happened at school on a regular school day & & 2.67 & 1.29 \\
\hline $\begin{array}{l}\text { Parental supervision } \\
\text { from "never" (1) to "always" (5) }\end{array}$ & .85 & 3.91 & 1.24 \\
\hline You must have parental permission before you go out during the weeknights & & 4.35 & 1.19 \\
\hline $\begin{array}{l}\text { If you go out on a Saturday evening, you must inform your parents beforehand about who will be along as } \\
\text { well as where you will be going }\end{array}$ & & 4.33 & 1.15 \\
\hline $\begin{array}{l}\text { If you have been out past curfew, your parents require that you explain why and tell who you were with } \\
\text { Your parents demand that they know where you are in the evenings, who }\end{array}$ & & 3.96 & 1.31 \\
\hline You are going to be with, and what you are going to do & & 4.14 & 1.16 \\
\hline You must ask your parents before you can make plans with friends about & & & \\
\hline What you will do on a Saturday night & & 4.08 & 1.31 \\
\hline Your parents require that you tell them how you spend your money & & 2.60 & 1.33 \\
\hline Warmth & .88 & 3.27 & .74 \\
\hline from "totally false" (1) to "totally true" (4) & & & \\
\hline Your parents let you know they love you & & 3.32 & .74 \\
\hline Your parents enjoy being with you & & 3.33 & .69 \\
\hline Your parents are always glad to see you & & 3.23 & .75 \\
\hline Your parents think you are special & & 3.20 & .77 \\
\hline $\begin{array}{l}\text { Rejection } \\
\text { from "totally false" (1) to "totally true" (4) }\end{array}$ & .79 & 1.79 & .87 \\
\hline Sometimes you wonder if your parents like you & & 1.95 & .99 \\
\hline Your parents think you are always in the way & & 1.72 & .80 \\
\hline Your parents make you feel like you are not wanted & & 1.43 & .69 \\
\hline Nothing you do is good enough for your parents & & 2.05 & .96 \\
\hline $\begin{array}{l}\text { Structure } \\
\text { from "totally false" (1) to "totally true" (4) }\end{array}$ & .78 & 2.99 & .79 \\
\hline When you want to do something, your parents show you how & & 2.72 & .78 \\
\hline When you want to understand how something works, your parents explain it to you & & 3.08 & .73 \\
\hline If you ever have a problem, your parents help you figure out what to do about it & & 3.17 & .75 \\
\hline Your parents explain the reasons for your family rules & & 2.99 & .90 \\
\hline $\begin{array}{l}\text { Chaos } \\
\text { from "totally false" (1) to "totally true" (4) }\end{array}$ & .79 & 2.25 & .93 \\
\hline When your parents make a promise, you don't know if they will keep it & & 2.31 & .97 \\
\hline When your parents say they will do something, sometimes they don't really do it & & 2.52 & .89 \\
\hline Your parents keep changing the rules on you & & 1.89 & .86 \\
\hline Your parents get mad at you with no warning & & 2.28 & .98 \\
\hline $\begin{array}{l}\text { Autonomy support } \\
\text { from "totally false" (1) to "totally true" (4) }\end{array}$ & .82 & 3.22 & .79 \\
\hline
\end{tabular}


Table I. (Continued).

\begin{tabular}{|c|c|c|c|}
\hline Construct & a & Mean & $S D$ \\
\hline Your parents trust you & & 3.17 & .83 \\
\hline Your parents accept you for yourself & & 3.40 & .75 \\
\hline Your parents let you do the things you think are important & & 3.37 & .71 \\
\hline Your parents try to understand your point of view & & 2.95 & .85 \\
\hline $\begin{array}{l}\text { Coercion } \\
\text { from "totally false" (1) to "totally true" (4) }\end{array}$ & .71 & 2.22 & .82 \\
\hline Your parents are always telling you what to do & & 2.44 & .80 \\
\hline Your parents boss you & & 2.63 & .84 \\
\hline Your parents think there is only one right way to do things - their way & & 2.22 & .94 \\
\hline Your parents say "no" to everything & & 1.58 & .66 \\
\hline
\end{tabular}




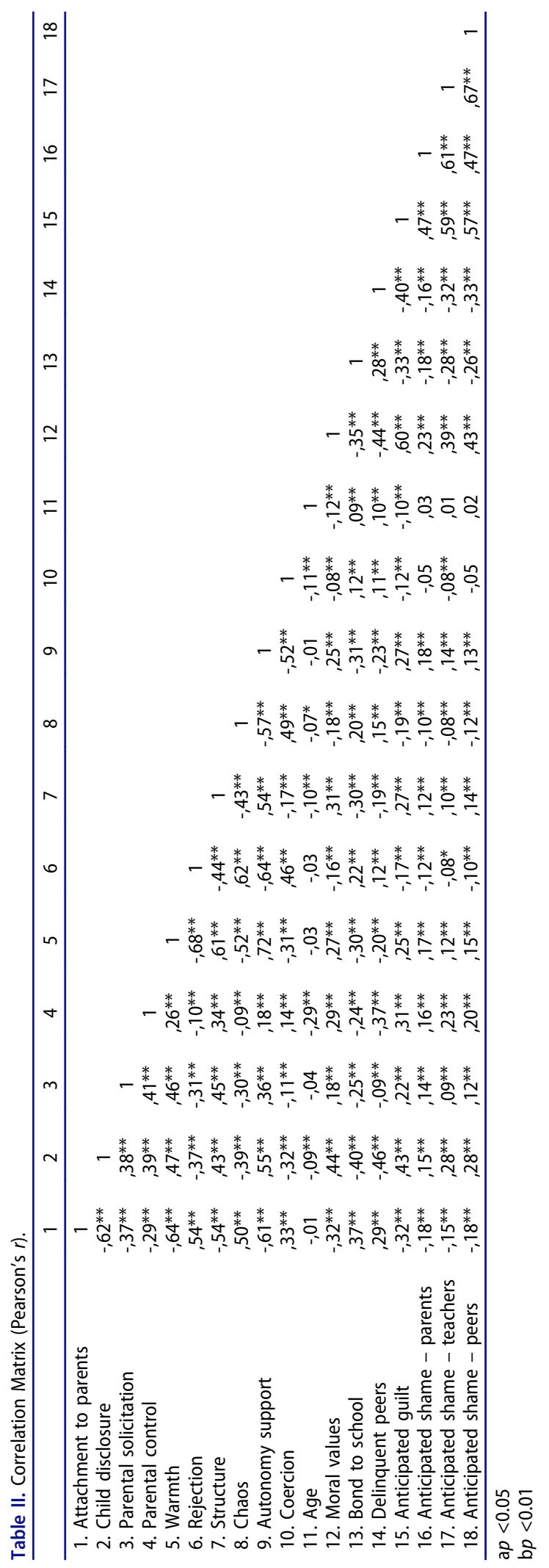


Table III. Latent class analysis - models with 1 to 6 classes $(N=1120)$.

\begin{tabular}{lccccccc}
\hline Models & $\begin{array}{c}\text { Number } \\
\text { of classes }\end{array}$ & AIC & BIC & BIC & Entropy & Sizes & Bootstrap \\
\hline Model 1 & 1 class & 31634 & 31734 & 31670 & na & 1120 & na \\
Model 2 & 2 classes & 28622 & 28778 & 28679 & 0.882 & $346 ; 774$ & 0.0000 \\
Model 3 & 3 classes & 27533 & 27744 & 27611 & 0.890 & $550 ; 95 ; 475$ & 0.0002 \\
Model 4 & 4 classes & 27148 & 27414 & 27246 & 0.870 & $28 ; 438 ; 460 ; 194$ & 0.0122 \\
Model 5 & 5 classes & 26900 & 27222 & 27018 & 0.866 & $27 ; 389 ; 457 ; 83 ; 164$ & 0.3665 \\
Model 6 & 6 classes & 26681 & 27058 & 26819 & 0.868 & $69 ; 394 ; 156 ; 97 ; 379 ; 25$ & 0.0698 \\
\hline
\end{tabular}

Table IV. Distribution of adolescents in the three classes.

\begin{tabular}{|c|c|c|c|}
\hline & Class 1 & Class 2 & Class 3 \\
\hline$N$ tot $(1,120)(\%)$ & 550 (49.11\%) & 95 (8.48\%) & 475 (42.41\%) \\
\hline$n$ adjudicated (120) (\%) & 47 (39.17\%) & $23(19.17 \%)$ & $50(41.67 \%)$ \\
\hline Girls (30) (\%) & 7 (23.33\%) & $11(36.67 \%)$ & $12(40.00 \%)$ \\
\hline Boys (90) (\%) & 40 (44.44\%) & $12(13.33 \%)$ & $38(42.22 \%)$ \\
\hline$n$ nonadjudicated $(1,000)(\%)$ & $503(50.30 \%)$ & $72(7.20 \%)$ & $425(42.50 \%)$ \\
\hline Girls (561) (\%) & $286(50.98 \%)$ & $50(8.91 \%)$ & $225(40.11 \%)$ \\
\hline Boys (439) (\%) & $217(49.43 \%)$ & $22(5.01 \%)$ & $200(45.56 \%)$ \\
\hline
\end{tabular}

